BMJ Open

Diabetes

Research

\& Care

\title{
Future of information technology and telecommunication in type 1 diabetes clinical care: results of an online survey
}

\author{
Daniela Haluza, ${ }^{1}$ Samantha Lang, ${ }^{2}$ Helen Rogers, ${ }^{3}$ Sophie Harris, ${ }^{3}$ \\ David Jungwirth, ${ }^{1}$ Pratik Choudhary, ${ }^{2}$ Ingrid Schuetz-Fuhrmann, ${ }^{4}$ \\ Marietta Stadler (i) ${ }^{2}$
}

To cite: Haluza D, Lang S, Rogers $\mathrm{H}$, et al. Future of information technology and telecommunication in type 1 diabetes clinical care: results of an online survey. BMJ Open Diab Res Care 2019;7:e000917. doi:10.1136/ bmjdrc-2019-000917

- Additional material is published online only. To view please visit the journal online (http://dx.doi.org/10.1136/ bmjdrc-2019-000917).

DH and SL contributed equally.

Received 19 September 2019 Revised 4 November 2019 Accepted 18 November 2019

Check for updates

(c) Author(s) (or their employer(s)) 2019. Re-use permitted under CC BY. Published by BMJ.

${ }^{1}$ Department of Environmental Health, Medical University of Vienna, Vienna, Austria ${ }^{2}$ Diabetes Research Group, King's College London, London, UK

${ }^{3}$ Diabetes, King's College Hospital, London, UK ${ }^{4} 3$ rd Medical Department, Hietzing Hospital Vienna, Vienna, Austria

Correspondence to Dr Marietta Stadler; marietta.stadler@kcl.ac.uk

\section{ABSTRACT}

Objective To assess the attitude of people living with type 1 diabetes toward the use of information and communication technology (ICT) to facilitate access to diabetes healthcare professionals (HCPs).

Research design and methods We conducted a crosssectional online survey in two European tertiary diabetes care centers in London, UK, and Vienna, Austria, and from online diabetes platforms. Participants were asked about general options of online diabetes care and were presented with three scenarios (teleconference, online chat and telemonitoring of continuous glucose monitoring traces). Results In total, 294 people (59\% female; 78 British, 164 Austrians, 47 Germans, 5 from other countries; $45 \pm 15$ years) who had been living with type 1 diabetes for $26 \pm 14.5$ years participated. The vast majority of participants were insulin pump (and/or glucose sensor) users (84\%) and reported good glycemic control $(31 \%$ with hemoglobin A1c ( $\mathrm{HbA1C})<7 \%$ and $51 \%$ with $\mathrm{HbA} 1 \mathrm{C}$ $7 \%-8 \%$ ). ICT was generally acceptable for counseling, with email/online messaging services and online health platform the most preferred options (74\% and $53 \%$ ). Study participants expressed a neutral to positive attitude toward the combined theme scores (relationship with HCP; confidence using technology; trust in data protection; intrusion of patient privacy; general acceptance of ICT in healthcare). UK participants showed more positive attitudes toward ICT across all theme scores than participants from Austria and Germany, but there were no gender-related differences.

Conclusions This online survey identified a highly ICT-astute group of people with type 1 diabetes, already using technology for insulin delivery, for whom online supported clinical diabetes care would be a viable and welcomed option.

\section{INTRODUCTION}

Type 1 diabetes mellitus requires lifelong intensive day-to-day self-management involving glucose monitoring, insulin injections adjusted to carbohydrate intake, exercise and illness, carbohydrate counting, and self-motivational skills. ${ }^{1}$ People with type 1 diabetes need regular face-to-face clinical encounters for advice, often necessitating time away from work and significant travel time. ${ }^{2}$ Health technology (smartphone applications, websites, computerized

\section{Significance of this study}

What is already known about this subject?

- People living with type 1 diabetes show a preference using communication technology that facilitates communication with healthcare professionals.

What are the new findings?

- We found that participants from the UK were more enthusiastic about information and communication technology (ICT) use in diabetes care than those from Austria/Germany.

- Men and women differed in their preferences regarding diabetes data management and online interaction with healthcare professionals.

How might these results change the focus of research or clinical practice?

- Targeted, user-centric, ICT-based diabetes care offers valuable features from health service user perspective which could be immediately translated into clinical practice.

recordings of blood glucose monitoring and online support forums) may facilitate daily disease management. Satisfaction with these technologies is considerable, with the most influential features being healthcare professional (HCP) involvement, facilitating feedback on diabetes self-management from a trained professional, and a sense of feeling supported in diabetes self-management. ${ }^{3}$ Online clinic appointments and patient professional online platforms could provide a convenient, costeffective way for people to access specialist advice.

Previous, smaller studies have evaluated the attitudes and acceptability of using online interaction with HCPs, but only as part of testing devices and communication methods rather than as the main focus. ${ }^{45}$ Some people with diabetes would value a virtual clinic site, stating that 'Ask an Expert' or 'peer support features' would be the most useful. ${ }^{6}$ Online interventions such as HCP online monitoring 
of blood glucose with text message and online appointment advice services have been shown to be effective at reducing patient hemoglobin A1c (HbA1c) levels, ${ }^{7}$ but also raise concerns regarding privacy and online data protection. ${ }^{8}$ No study has previously assessed all of these domains in a group of people with type 1 diabetes, whose clinical care takes place within a hospital clinic.

In this study we report on attitudes of people with type 1 diabetes toward online communication with HCPs across two European tertiary diabetes care centers in London, UK, and Vienna, Austria. We assessed attitudes toward online care across five themes, namely relationships with HCPs, privacy, practical benefits, worries around data protection and confidence in technology use, also introducing three potential scenarios providing a realistic impression of real-life information and communication technology (ICT) use.

\section{PARTICIPANTS AND METHODS}

We conducted a cross-sectional online survey among a sample of people receiving diabetes care in two large tertiary diabetes centers: King's College Hospital (KCH) in London, UK; and Hietzing Hospital Vienna (HHV), in Vienna, Austria. All people with type 1 diabetes attending an outpatient appointment within 2 years of the start of the study were invited to participate. Inclusion criteria were being at least 18 years of age and having a diagnosis of type 1 diabetes for more than 6 months. Patients were excluded if they had gestational diabetes, type 2 diabetes or were participating in other ongoing diabetes studies.

An online link sent to all participants (HHV: direct; $\mathrm{KCH}$ : after initial postal contact) enabled access to the online participant information and the study questionnaire between 24 July 2015 and 1 March 2016 via the software package SoSci Survey. ${ }^{9}$ The link to the survey was also posted on social media platforms and on the mySugr user platform. $^{10}$

Participants were informed about the purpose of the study. Survey participation was voluntary and anonymous; no identifying information was collected. Consent was provided by checking a tick box at the start of the study. Source of referral to the study was collected to allow subgroup analysis. The collected data were stored securely and protected from unauthorized access.

The online survey link was clicked 637 times. The questionnaire was partly completed 380 times and fully completed 294 times, resulting in a response rate of $60 \%$ and a full cooperation rate of $47 \%$. Participants took a mean $\pm \mathrm{SD}$ of $16.7 \pm 5.5 \mathrm{~min}$ (range $4.7-31.8 \mathrm{~min}$ ) to fill in the survey online. KCH sent out 474 invite letters and HHV (IS-F) 308 invite emails. Retrospectively, we excluded three participants who were younger than 18 years, resulting in a final data set of 294 completed questionnaires.

We developed a study questionnaire in English, which was then translated into German by a native speaker (MS) using forward and backward translation. At $\mathrm{KCH}$, one of the authors (SL) attended a voluntary focus group of people with type 1 diabetes to ensure the study's acceptability and feasibility among its target group.

The online questionnaire consisted of 47 items. Seven sections assessed (1) sociodemographic characteristics and general information, (2) diabetes history, (3) diabetes service use, (4) current information technology (IT) usage, (5) HCP interaction, (6) anonymity and data protection and (7) scenarios. In the questionnaire, items in sections 5-7 were assigned to one of the following themes: relationship with HCP will improve (relationship score), confidence using technology (technology score), trust in data protection (data protection score), worry about intrusion of the patient's privacy (privacy score), and general acceptance of ICT (acceptance score).

These themes were not disclosed to study participants to avoid bias. The items assessing these themes were validated by three researchers blinded to the coding of the questions (ie, which theme they belonged to); those questions with discordant coding were redesigned and revalidated. A pretest of 20 volunteers assessed the usability and comprehensibility of the survey, and we adapted items according to this feedback.

The three scenarios, video consultation, online chat, and 24/7 remote continuous glucose monitoring system (CGMS), represented possible ways of using ICT in a patient-HCP interaction. All scenarios were already technologically feasible and had been used in clinical studies or as pilot trials for real-life clinical services (online supplementary material table S1). ${ }^{11-13}$

We analyzed fully completed questionnaires with less than $5 \%$ missing values. For the majority of items, we used 5 -point Likert scales ranging from 1=strongly disagree to $5=$ strongly agree. Descriptive data were presented as mean, median, SD, and percentage. Values not adding up to $100 \%$ are due to missing data. Relationship, technology, trust, privacy and acceptance scores were obtained by summing up the answers to the items targeted at that theme. The combined score included summed responses to all items of the themes. Cronbach's alpha assessed the reliability and internal consistency of the scales.

$\chi^{2}$ tests and t-tests assessed subgroup differences for country, digital age groups, and gender regarding categorical and ordinal variables. For country-specific differences, we compared participants from the UK with those from the German-speaking countries, that is, Austria (AUT) and Germany (GER), reflecting the study questionnaire language options German and English and assuming similar attitudes among patients with diabetes in the respective countries. The UK group $(n=78,56 \%$ female) consisted of $85 \%(n=66)$ participants recruited by $\mathrm{KCH}$ and $14 \% \quad(\mathrm{n}=12)$ participating via online platforms, whereas the AUT/GER group ( $n=211,61 \%$ female) consisted of $75 \%(\mathrm{n}=158)$ participants recruited by HHV and $25 \%(\mathrm{n}=53)$ participating via online platforms. For digital age-specific differences, we followed the definitions coined by Prensky ${ }^{14}$ with digital natives being those 'born digital' and born in or after 1980, whereas digital immigrants are defined as those born before 
1980, as defined by Palfrey and Gasser. ${ }^{15}$ We conducted a subgroup analysis by educational level to compare the theme scores between these groups, using analysis of variance and post-hoc Bonferroni.

Data were processed and analyzed using Excel (Microsoft, Seattle, Washington) and SPSS V.23. The two-tailed level of statistical significance was set at 0.05 .

\section{RESULTS}

In total, 294 patients completed our survey. Of these, 211 (72\%) participants were from Austria (164) or Germany (47), 78 (27\%) from the UK, and $5(2 \%)$ had other nationalities: Switzerland ( $\mathrm{n}=2)$, Barbados, Spain, and USA (1 each). All of the non-UK, non-Austrian participants indicated they had heard about the survey via online platforms. Participants ( $\mathrm{N}=294,60 \%$ female) were $44.9 \pm 15.0$ years old (range 19-85 years). The majority were digital immigrants $(\mathrm{n}=206,70 \%) ; 88$ individuals $(30 \%)$ were digital natives. The majority of respondents had a university degree (36.\%) or higher education certificate (28\%), 22\% had A-levels or equivalent and $10 \%$ had completed secondary school, and only $1 \%$ with primary school education.

Overall, $84 \%$ indicated daily ICT use for on average just below 5 hours daily, spread evenly across mobile devices (mean \pm SD 1.7 \pm 0.4 hours) and home internet (mean \pm SD $1.7 \pm 0.4$ hours). Work internet use was marginally less at a mean \pm SD of $1.4 \pm 0.5$ hours.

Participants had been living with diabetes for $26.0 \pm 14.5$ years (range 2-69 years). The vast majority were insulin pump users (84\%), 22\% of whom also used CGMS, followed by patients applying multiple daily insulin injection therapy. More than half (51\%) stated that their latest HbAlc was between $7.0 \%$ and $8.0 \%, 31 \%$ below $7.0 \%$, and only $14 \%$ reported an HbAlc above $8 \%$. The vast majority $(81 \%)$ stated that they had no diabetes-related complications, $14 \%$ declared one, $4 \%$ two, and $1.4 \%$ three diabetes complications. Nine per cent had experienced a diabetes-related inpatient hospital stay ( $1 \%$ more than five stays, $1 \%$ three, $2 \%$ two and $5 \%$ one stay) in the anteceding 12 months. The majority of participants agreed (strongly) that their diabetes is well controlled $(71 \%)$ and their health is good (69\%). Most participants reported to contact their HCP less than once per month (64\%), whereas $25 \%$ did so two to four times per month and $11 \%$ weekly or more often. Most $(84 \%)$ used ICT daily in their personal and work life, and a third for more than 3 hours per day.

A majority (69\%) stated a preference for at least half of their diabetes care to be delivered by online counseling. Online messaging services for general queries concerns and a diabetes profile on an online health platform were the most preferred options ( $74 \%$ and $53 \%$ ), while video conferencing $(31 \%)$ was the least preferred (table 1 ).

Table 2 depicts the scores for the five themes of online interaction. The levels of all scores were moderate, with the median reaching $50 \%-64 \%$ of the respective maximum score: relationship score 55\%, technology score $50 \%$, data protection score $55 \%$, privacy score $60 \%$, general acceptance score $64 \%$, and combined score $59 \%$. Measures of reliability varied between the scores of the themes: relationship score alpha $=0.597$, technology score alpha $=0.745$, data protection score alpha $=0.694$ (all: 4 items), privacy score alpha $=0.554$ (3 items), and general acceptance score alpha $=0.604$ (11 items), with good internal consistency for the combined score (alpha $=0.889$, 26 items). All scenarios showed good internal reliability: video conference alpha $=0.824$ ( 6 items), remote CGMS alpha $=0.824$ ( 7 items $)$, and online chat alpha $=0.890 \quad(6$ items). Participants were, on average, neutral in their confidence using ICT, found IT generally acceptable, and were neutral with regard to worries regarding intrusion on privacy and trust in data protection.

The scenarios were perceived as neutral to slightly positive (video conference (3.1; 2.8-3.3), remote CGMS (3.1; 2.4-3.3), and online chat (3.2; 2.9-3.4), score range $1-5)$, although there were concerns regarding data upload and CGMS use. Video clinics were preferred to face-to-face clinics by $39 \%$, whereas $33 \%$ would be more likely to contact their $\mathrm{HCP}$ with problems if an online chat facility existed, and $34 \%$ agreed that they would use remote CGMS if they were to develop problematic hypoglycemia.

\section{Subgroup analyses}

Participants from the UK were more likely to have internet at home and at work, but in both countries more than $70 \%$ had internet access via a mobile device (all: $\mathrm{p}<0.05$; table 3). Participants from AUT/GER were more likely to use an insulin pump and were downloading glucometer, pump or CGMS data more often than their English counterparts (all: $\mathrm{p}<0.05$; table 4 ). Despite this, participants from AUT/GER were more reticent to engage with HCPs online, with differences regarding online messaging, text messaging, online feedback of self-monitoring, and CGMS remote monitoring (all: $\mathrm{p}<0.05$; table 1 ). Participants from AUT/GER were younger $(42.9 \pm 14.6$ years) than the UK participants $(50.8 \pm 14.4$ years, $\mathrm{p}<0.001)$, resulting in a higher proportion of digital natives ( $33 \%$ vs $15 \%, \mathrm{p}=0.001$ ).

This reluctance was also seen when analyzing the five themes of online interaction, assessing relationship with HCPs online, trust in data protection, confidence with technology, concerns regarding personal privacy and general acceptance of health technologies online (table 2). UK participants showed higher approval for all themes (all: $\mathrm{p}<0.001$ ) compared with participants from AUT/GER. UK participants also showed more positive attitudes toward HCP interaction online, a higher confidence in technology use, and were generally more accepting of integrating technology into their diabetes healthcare management. AUT/GER participants were more concerned about their online data protection and invasion of their privacy when using online health technologies than UK participants.

Digital natives were more likely to use the internet on a daily basis, access the internet on a mobile device compared with digital immigrants (both: $\mathrm{p}<0.001$ ) and have internet at home $(\mathrm{p}<0.05$; table 3$)$. Digital natives 
Table 1 Online counseling preferences and subgroup differences (country, digital age, gender). Data are presented as number of participants (\%)

\begin{tabular}{|c|c|c|c|c|c|c|c|c|c|c|}
\hline & \multicolumn{3}{|l|}{ Country } & \multicolumn{3}{|c|}{ Digital age } & \multicolumn{3}{|l|}{ Gender } & \multirow[b]{2}{*}{$\begin{array}{l}\text { Total } \\
\mathrm{N}=294\end{array}$} \\
\hline & $\begin{array}{l}\text { UK } \\
n=78\end{array}$ & $\begin{array}{l}\text { Austria/Germany } \\
\mathrm{n}=211\end{array}$ & $\begin{array}{l}P \\
\text { value }\end{array}$ & $\begin{array}{l}\text { Digital } \\
\text { natives } \\
\mathrm{n}=88\end{array}$ & $\begin{array}{l}\text { Digital } \\
\text { immigrants } \\
n=206\end{array}$ & $P$ value & $\begin{array}{l}\text { Female } \\
n=174\end{array}$ & $\begin{array}{l}\text { Male } \\
n=118\end{array}$ & $P$ value & \\
\hline \multicolumn{11}{|c|}{ Healthcare professional contact preferred frequency } \\
\hline$\geq 1 /$ week & $10(12.8)$ & $21(10.0)$ & 0.8 & $11(12.5)$ & $20(9.7)$ & 0.1 & $27(15.5)$ & $4(3.4)$ & 0.001 & $31(10.7)$ \\
\hline $2-4 /$ month & $19(24.4)$ & $53(25.1)$ & & $28(31.8)$ & $45(21.8)$ & & $50(28.7)$ & $22(18.6)$ & & $73(25.1)$ \\
\hline$<1 /$ month & $48(61.5)$ & $135(64.0)$ & & $49(55.7)$ & $138((67.0)$ & & $97(55.7)$ & $89(75.4)$ & & $187(64.3)$ \\
\hline \multicolumn{11}{|c|}{ Individual vs group interaction online } \\
\hline One-to-one & $49(62.8)$ & $129(61.1)$ & 1.0 & $50(56.8)$ & $132(64.1)$ & 0.02 & $103(59.2)$ & $78(66.1)$ & 0.5 & $182(64.1)$ \\
\hline Group & $1(1.3)$ & $2(0.9)$ & & $3(3.4)$ & $0(0.0)$ & & $2(1.1)$ & $1(0.8)$ & & $3(1.1)$ \\
\hline Either/both & 26 (33.3) & $72(34.1)$ & & $34(38.6)$ & $65(31.6)$ & & $63(36.2)$ & $35(29.7)$ & & $99(34.9)$ \\
\hline \multicolumn{11}{|c|}{ Video conferencing } \\
\hline Yes & 28 (35.9) & $59(28.0)$ & 0.2 & $26(29.5)$ & $64(31.1)$ & 0.8 & $48(27.6)$ & $42(35.6)$ & 0.2 & $90(30.6)$ \\
\hline No & $50(64.1)$ & $152(72.0)$ & & $62(70.5)$ & $142(68.9)$ & & $126(72.4)$ & $76(64.4)$ & & $204(69.4)$ \\
\hline \multicolumn{11}{|c|}{ Online messaging } \\
\hline Yes & $70(89.7)$ & $134(67.8)$ & $<0.001$ & $70(79.5)$ & $148(71.8)$ & 0.2 & $138(79.3)$ & 79 (66.9) & 0.02 & $218(74.1)$ \\
\hline No & $8(10.3)$ & $68(32.2)$ & & $18(20.5)$ & $58(28.2)$ & & $36(20.7)$ & $39(33.1)$ & & $76(25.9)$ \\
\hline Text messagins & & & & & & & & & & 105 (35.7) \\
\hline Yes & $38(48.7)$ & $65(30.8)$ & 0.01 & $33(37.5)$ & $72(35.0)$ & 0.7 & $73(42.0)$ & $32(27.1)$ & 0.01 & $105(35.7)$ \\
\hline No & $40(51.3)$ & $146(69.2)$ & & $55(62.5)$ & $134(65.0)$ & & $101(58.0)$ & $86(72.9)$ & & $189(64.3)$ \\
\hline \multicolumn{11}{|c|}{ Online feedback of self-monitoring } \\
\hline Yes & $47(60.3)$ & $94(44.5)$ & 0.01 & $49(55.7)$ & $96(46.6)$ & 0.2 & $96(55.2)$ & $49(41.5)$ & 0.02 & $145(49.3)$ \\
\hline No & $31(39.7)$ & $117(55.5)$ & & $39(44.3)$ & $110(53.4)$ & & $78(44.8)$ & $69(58.5)$ & & $149(50.7)$ \\
\hline \multicolumn{11}{|c|}{ Continuous glucose remote monitoring } \\
\hline Yes & $34(43.6)$ & $57(27.0)$ & 0.01 & $27(30.7)$ & $65(31.6)$ & 0.9 & $53(30.5)$ & $39(33.1)$ & 0.6 & $92(31.3)$ \\
\hline No & $44(56.4)$ & $154(73.0)$ & & $61(69.3)$ & $141(68.4)$ & & $121(69.5)$ & 79 (66.9) & & $202(68.7)$ \\
\hline \multicolumn{11}{|c|}{ Online diabetes profile } \\
\hline Yes & $45(57.7)$ & $107(50.7)$ & 0.3 & $50(56.8)$ & $106(51.5)$ & 0.4 & $94(54.0)$ & $60(50.8)$ & 0.6 & $156(53.1)$ \\
\hline No & $33(42.3)$ & $104(49.3)$ & & $38(43.2)$ & $100(48.5)$ & & $80(46.0)$ & $58(49.2)$ & & $138(46.9)$ \\
\hline \multicolumn{11}{|c|}{ No healthcare professional contact online } \\
\hline Yes & $2(2.6)$ & $19(9.0)$ & 0.07 & $5(5.7)$ & $16(7.8)$ & 0.5 & $11(6.3)$ & $10(8.5)$ & 0.5 & $21(7.1)$ \\
\hline No & $76(97.4)$ & $192(91.0)$ & & $83(94.3)$ & $190(92.2)$ & & $163(93.7)$ & $108(91.5)$ & & $273(92.9)$ \\
\hline
\end{tabular}

Values not adding up to $100 \%$ are due to missing data.

were less likely to use technologies related to their diabetes care (insulin pump therapy, glucometer and CGMS downloads, all: $\mathrm{p}<0.05$; table 4 ). The majority of participants downloaded their glucometer and pump less often than every 3 months ( $61 \%$ and $53 \%)$; this proportion was higher in the digital native group (71\%). With regard to interacting with HCPs online, digital natives were less concerned regarding interacting with a group rather than on an individual 1:1 capacity compared with digital immigrants $(p<0.05)$.

Digital natives consistently scored lower across all theme scores, reaching significance for the technology score (mean 10.9, SD 4.4 vs mean 12.0, SD 4.3) as well as the data protection score (mean 11.1, SD 4.0 vs 12.5 , SD 3.7, both: $\mathrm{p}<0.05$; table 2). Compared with digital immigrants, digital natives were, despite a higher IT use (table 3), less confident at using IT and also more worried regarding data protection issues (table 2). However, the two groups were similar in their attitudes toward online HCP interaction (table 1).

Both genders had a similar proportion of daily IT usage, but more men than women had internet access at home and work (both: $\mathrm{p}<0.05$; table 3 ). Men were more likely to use a pump and to download diabetes data from glucometer, pump and CGMS more frequently (all: $\mathrm{p}<0.05$; table 4 ). Female participants had a higher preference for more frequent online interaction with HCPs via online messaging, instant text messaging and online messaging and feedback on blood glucose reading downloads (all: $\mathrm{p}<0.05$; table 1 ). Female and male participants yielded similar scores for all themes (table 2).

Participants with tertiary level education scored higher on all theme scores than people with secondary education (table 2). 
Table 2 Scores of online interaction themes and subgroup differences (country, digital age, gender)

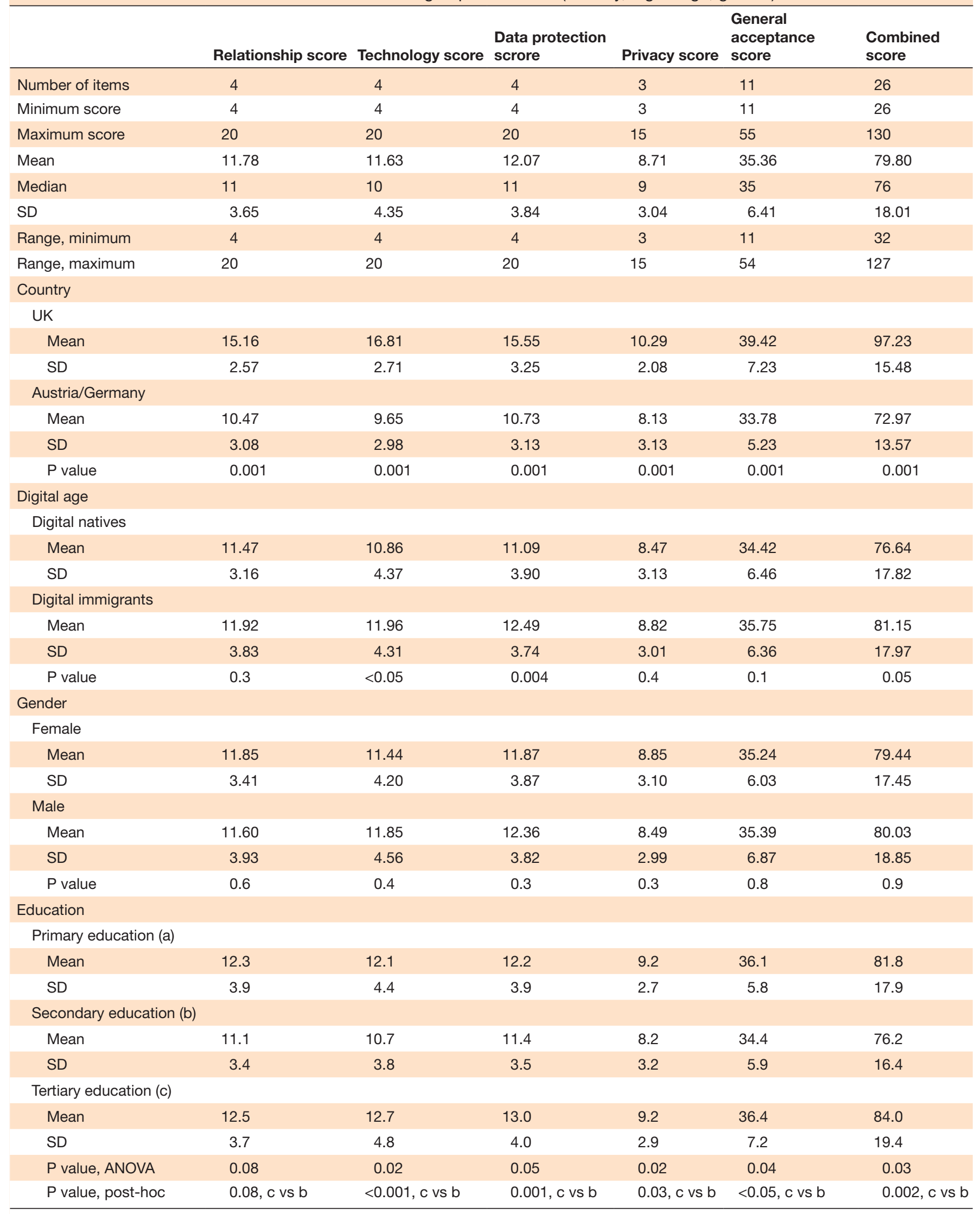

ANOVA, analysis of variance. 
Table 3 IT usage in different day-to-day settings plus IT use frequency by country, digital age, and gender, $\mathrm{n}(\%)$

\begin{tabular}{|c|c|c|c|c|c|c|c|c|c|c|}
\hline & \multicolumn{3}{|l|}{ Country } & \multicolumn{3}{|c|}{ Digital age } & \multicolumn{3}{|l|}{ Gender } & \multirow[b]{2}{*}{$\begin{array}{l}\text { Total } \\
\mathrm{N}=294 \\
\end{array}$} \\
\hline & $\begin{array}{l}\text { UK } \\
n=78\end{array}$ & $\begin{array}{l}\text { Austria/ } \\
\text { Germany } \\
\mathrm{n}=\mathbf{2 1 1}\end{array}$ & $P$ value & $\begin{array}{l}\text { Digital } \\
\text { natives } \\
n=88\end{array}$ & $\begin{array}{l}\text { Digital } \\
\text { immigrants } \\
\mathrm{n}=206\end{array}$ & $P$ value & $\begin{array}{l}\text { Female } \\
n=174\end{array}$ & $\begin{array}{l}\text { Male } \\
n=118\end{array}$ & $P$ value & \\
\hline \multicolumn{11}{|c|}{ Daily IT usage } \\
\hline Yes & $66(84.6)$ & 177 (83.9) & 0.880 & 85 (96.6) & $163(79.1)$ & $0.001^{\star \star}$ & $146(83.9)$ & $101(85.6)$ & 0.696 & $248(84.4)$ \\
\hline No & $12(15.4)$ & $34(16.1)$ & & $3(3.4)$ & 43 (20.9) & & $28(16.1)$ & $17(14.4)$ & & $46(15.6)$ \\
\hline \multicolumn{11}{|c|}{ Internet at home } \\
\hline Yes & $76(97.4)$ & $137(64.9)$ & $0.001^{\star *}$ & $54(61.4)$ & $163(79.1)$ & $0.002^{*}$ & $116(66.7)$ & 99 (83.9) & $0.001^{\star *}$ & $217(73.8)$ \\
\hline No & $2(2.6)$ & $74(35.1)$ & & $34(38.6)$ & 43 (20.9) & & $58(33.3)$ & $19(16.1)$ & & 77 (26.2) \\
\hline \multicolumn{11}{|c|}{ Internet at work } \\
\hline Yes & $39(50.0)$ & $67(31.8)$ & $0.004^{*}$ & 34 (38.6) & 76 (36.9) & 0.777 & $56(32.2)$ & $54(45.8)$ & $0.019^{*}$ & $110(37.4)$ \\
\hline No & $39(50.0)$ & 144 (68.2) & & $54(61.4)$ & $130(63.1)$ & & $118(67.8)$ & 64 (54.2) & & $184(62.6)$ \\
\hline \multicolumn{11}{|c|}{ Mobile internet access } \\
\hline Yes & $56(71.8)$ & $159(75.4)$ & 0.538 & 84 (95.5) & $136(66.0)$ & $0.001^{\star *}$ & $136(78.2)$ & $84(71.2)$ & 0.175 & $220(74.8)$ \\
\hline No & $22(28.2)$ & $52(24.6)$ & & $4(4.5)$ & $70(34.0)$ & & 83 (21.8) & $34(28.8)$ & & 74 (25.2) \\
\hline
\end{tabular}

Values not adding up to $100 \%$ are due to missing data.

${ }^{*} \mathrm{P}<0.05,{ }^{*} \mathrm{P}<0.01$.

IT, information technology.

\section{DISCUSSION}

This online survey among adults living with type 1 diabetes analyzed prevailing attitudes and modes of telecare in the context of the patient-web-physician triangle. ${ }^{16}$ The respondents, who were recruited from large tertiary type 1 diabetes outpatient services, were astute ICT users in their daily life, with the majority using advanced diabetes technology to manage their diabetes. The vast majority had good glycemic control and no diabetes complications in spite of living with diabetes for on average more than 25 years, suggesting a high level of commitment to diabetes self-care.

Table 4 Current usage of diabetes-related technology subgroup analysis and acceptability of different modes of interaction by country, digital age, and gender, $\mathrm{n}(\%)$

\begin{tabular}{|c|c|c|c|c|c|c|c|c|c|c|}
\hline & \multicolumn{3}{|l|}{ Country } & \multicolumn{3}{|c|}{ Digital age } & \multicolumn{3}{|l|}{ Gender } & \multirow[b]{2}{*}{$\begin{array}{l}\text { Total } \\
\mathbf{N}=294\end{array}$} \\
\hline & $\begin{array}{l}\text { UK } \\
n=78\end{array}$ & $\begin{array}{l}\text { Austria/Germany } \\
\mathrm{n}=211\end{array}$ & $\begin{array}{l}P \\
\text { value }\end{array}$ & $\begin{array}{l}\text { Digital } \\
\text { natives } \\
n=88\end{array}$ & $\begin{array}{l}\text { Digital } \\
\text { immigrants } \\
n=206\end{array}$ & $\begin{array}{l}P \\
\text { value }\end{array}$ & $\begin{array}{l}\text { Female } \\
n=174\end{array}$ & $\begin{array}{l}\text { Male } \\
n=118\end{array}$ & $\begin{array}{l}P \\
\text { value }\end{array}$ & \\
\hline \multicolumn{11}{|l|}{ DM therapy } \\
\hline $\begin{array}{l}\text { Multiple } \\
\text { daily insulin } \\
\text { injection }\end{array}$ & $23(29.5)$ & $25(11.8)$ & 0.001 & $19(21.6)$ & $31(15.0)$ & 0.2 & 37 (21.4) & $13(11.2)$ & 0.02 & $48(16.4)$ \\
\hline $\begin{array}{l}\text { Insulin pump } \\
\text { therapy }\end{array}$ & $55(70.5)$ & $186(88.2)$ & & $69(78.4)$ & $175(85.0)$ & & $137(79.2)$ & $105(90.5)$ & & $244(83.0)$ \\
\hline \multicolumn{11}{|c|}{ Glucometer download } \\
\hline$<3 /$ month & 55 (70.5) & 111 (52.6) & 0.01 & $62(70.5)$ & $105(51.0)$ & 0.03 & $111(64.2)$ & $55(47.4)$ & 0.02 & $167(60.7)$ \\
\hline $1-3 /$ month & $8(10.3)$ & $49(32.2)$ & & $14(15.9)$ & 45 (21.8) & & $33(19.1)$ & $25(21.6)$ & & $59(21.5)$ \\
\hline$>1 /$ month & $8(10.3)$ & $40(19.0)$ & & $10(11.4)$ & 39 (18.9) & & $22(12.7)$ & 27 (23.3) & & $49(17.89$ \\
\hline \multicolumn{11}{|c|}{ Pump/CGMS download } \\
\hline$<3 /$ month & 47 (60.3) & $105(49.8)$ & 0.3 & 58 (65.9) & $96(46.6)$ & 0.01 & $104(60.1)$ & $50(43.1)$ & 0.01 & $154(52.6)$ \\
\hline $1-3 /$ month & $19(24.4)$ & $60(28.4)$ & & $20(22.7)$ & $60(29.1)$ & & $39(22.5)$ & $40(34.5)$ & & $80(27.3)$ \\
\hline$>1 /$ month & $12(15.4)$ & 45 (21.3) & & 10 (11.4) & 49 (23.8) & & $31(17.9)$ & $28(24.1)$ & & $59(20.1)$ \\
\hline \multicolumn{11}{|l|}{ Email download } \\
\hline$<3 /$ month & 73 (93.6) & $181(85.8)$ & 0.1 & $74(84.1)$ & $185(89.8)$ & 0.2 & 155 (89.6) & 102 (87.9) & 0.9 & $259(89.0)$ \\
\hline $1-3 /$ month & $3(3.8)$ & 24 (11.4) & & 12 (13.6) & $15(7.3)$ & & $15(8.7)$ & $12(10.3)$ & & 27 (9.3) \\
\hline$>1 /$ month & $1(1.3)$ & $4(1.9)$ & & $2(2.3)$ & $3(1.5)$ & & $3(1.7)$ & $2(1.7)$ & & $5(1.7)$ \\
\hline
\end{tabular}

CGMS, continuous glucose monitoring system; DM, diabetes mellitus. 
In general, attitudes toward ICT-mediated diabetes care delivered by their diabetes care teams were positive, which was reflected in a readiness to engage with all proposed modalities of ICT, including the three plausible clinical scenarios described. In comparison with studies in the general population, people living with diabetes are likely to have lower thresholds of engaging with technology for their self-care.

Technology acceptance differs between expert groups representing medical professionals, patient advocates and administrative personnel. ${ }^{17-19}$ Thus, closer cooperation between related stakeholders is vital for successful IT implementation and adoption. Also, readiness for telemonitoring was shown to be higher among patients compared with HCPs. ${ }^{20}$

Despite higher diabetes technology use, participants from the German-speaking countries were less enthusiastic about using ICT in their diabetes care than those in the UK. There is a potential cultural background to this finding, as Austrian internet users were shown to be skeptical regarding health data electronic exchange between HCPs and patients. ${ }^{22}{ }^{22}$ It is also likely that differences in access to tertiary healthcare between UK and AUT/GER ${ }^{23}$ influence the readiness to engage in ICT online diabetes care.

This study has several limitations. The response rate was quite low and there were more participants from Austria than London. While attempts were made to maximize the response rate by sending out multiple reminders to participate, the findings are not generalizable to all people with type 1 diabetes. Also, the cross-sectional study design did not allow determining temporal order, directions and causalities of observed associations. Only people with internet access could participate in this study. However, we strove at collecting information from current users of digital health technologies to assess their opinions and future care requirements.

This study identified a motivated group of people with type 1 diabetes, already using technology for insulin delivery, for whom, given their low threshold for ICT use and well-managed diabetes, online clinical care could be a viable and welcomed option. Closing the knowledge gap on health IT-related patients' expectations and opinions, this study adds so far lacking information on countryspecific, gender-specific, and digital age-specific divergences regarding the future direction of diabetes type 1 care in an increasingly digitized health system. This may contribute to guidance and policy-making regarding the future applications of clinical technology in caring for people with diabetes.

Acknowledgements We thank the people with type 1 diabetes for participating in the study. We are grateful to Anna Schuetz for her administrative support. We would like to thank Fredrik Debong for posting the link to our survey on the mySugr online platform.

Contributors MS, DH and SL designed the study. MS, SL, DH and DJ designed the online survey. PC, HR and SH contributed to the data analysis and interpretation. IS-F and SL collected the data. DH and MS conducted the data analysis. DH, SL and MS wrote the manuscript, which was revised and edited by all authors.
Funding This work was supported by a summer studentship to SL and was funded by a poster prize awarded by King's College London-Integrated Academic Training Programme to MS. MS's salary is funded by the National Institute of Health Research (NIHR) through a Clinician Scientist Fellowship award (CS-2017-17-023).

Competing interests None declared.

\section{Patient consent for publication Not required.}

Ethics approval This study was approved by the local ethical committees of the city of Vienna, Austria (EK 15-145-VK) and UK (EC 15/SC/0332), and conducted according to the guidelines of the Declaration of Helsinki.

Provenance and peer review Not commissioned; externally peer reviewed.

Data availability statement All data relevant to the study are included in the article or uploaded as supplementary information.

Open access This is an open access article distributed in accordance with the Creative Commons Attribution 4.0 Unported (CC BY 4.0) license, which permits others to copy, redistribute, remix, transform and build upon this work for any purpose, provided the original work is properly cited, a link to the licence is given, and indication of whether changes were made. See: https://creativecommons.org/ licenses/by/4.0/.

ORCID iD

Marietta Stadler http://orcid.org/0000-0001-6869-9960

\section{REFERENCES}

1 Nathan DM, Group DER, DCCT/EDIC Research Group. The diabetes control and complications trial/epidemiology of diabetes interventions and complications study at 30 years: overview. Diabetes Care 2014;37:9-16.

2 Heller S, Lawton J, Amiel S, et al. Improving management of type 1 diabetes in the UK: the dose adjustment for normal eating (DAFNE) programme as a research test-bed. A mixed-method analysis of the barriers to and facilitators of successful diabetes self-management, a health economic analysis, a cluster randomised controlled trial of different models of delivery of an educational intervention and the potential of insulin pumps and additional educator input to improve outcomes. Programme Grants for applied research 2014;5.

3 Harrison S, Stadler M, Ismail K, et al. Are patients with diabetes mellitus satisfied with technologies used to assist with diabetes management and coping?: a structured review. Diabetes Technol Ther 2014;16:771-83.

4 Mulvaney SA, Anders S, Smith AK, et al. A pilot test of a tailored mobile and web-based diabetes messaging system for adolescents. J Telemed Telecare 2012;18:115-8.

5 Powell J, Jennings A, Armstrong N, et al. Pilot study of a virtual diabetes clinic: satisfaction and usability. J Telemed Telecare 2009;15:150-2.

6 Lowe P, Hearnshaw H, Griffiths F. Attitudes of young people with diabetes to an Internet-based virtual clinic. J Telemed Telecare 2005;11:59-60.

7 Hsu WC, Lau KHK, Huang R, et al. Utilization of a cloud-based diabetes management program for insulin initiation and titration enables collaborative decision making between healthcare providers and patients. Diabetes Technol Ther 2016;18:59-67.

8 Hilliard M, Sparling K, Hitchcock J, et al. The emerging diabetes online community. Curr Diabetes Rev 2015;11:261-72.

9 SoSci Survey. Available: http://www.soscisurvey.de

10 MySugr. Available: https://mysugr.com

11 Nimri R, Muller I, Atlas E, et al. MD-Logic overnight control for 6 weeks of home use in patients with type 1 diabetes: randomized crossover trial. Diabetes Care 2014;37:3025-32.

12 Fatehi F, Martin-Khan M, Smith AC, et al. Patient satisfaction with video teleconsultation in a virtual diabetes outreach clinic. Diabetes Technol Ther 2015;17:43-8.

13 Boogerd EA, Noordam C, Kremer JAM, et al. Teaming up: feasibility of an online treatment environment for adolescents with type 1 diabetes. Pediatr Diabetes 2014;15:394-402.

14 Prensky M. Digital natives, digital immigrants Part 1. On the Horizon 2001;9:1-6.

15 Palfrey J, Gasser U. Born digital: understanding the first generation of digital natives. 13. Basic Books, 2008. ISBN: 978-0465005154.

16 Wald HS, Dube CE, Anthony DC. Untangling the Web--the impact of Internet use on health care and the physician-patient relationship. Patient Educ Couns 2007;68:218-24.

17 Haluza D, Jungwirth D. Ict and the future of healthcare: aspects of pervasive health monitoring. Inform Health Soc Care 2018;43:1-11. 
18 Haluza D, Jungwirth D. Ict and the future of health care: aspects of doctor-patient communication. Int J Technol Assess Health Care 2014;30:298-305.

19 Haluza D, Jungwirth D. Ict and the future of health care: aspects of health promotion. Int J Med Inform 2015;84:48-57.

20 Muigg D, Kastner P, Modre-Osprian R, et al. Is Austria ready for Telemonitoring? A readiness assessment among doctors and patients in the field of diabetes. Stud Health Technol Inform 2018;248:322-9.
21 Haluza D, Naszay M, Stockinger A, et al. Digital natives versus digital immigrants: influence of online health information seeking on the Doctor-Patient relationship. Health Commun 2017;32:1342-9.

22 Haluza D, Naszay M, Stockinger A, et al. Prevailing opinions on connected health in Austria: results from an online survey. Int $J$ Environ Res Public Health 2016;13:813.

23 McKnight JA, Wild SH, Lamb MJE, et al. Glycaemic control of Type 1 diabetes in clinical practice early in the 21 st century: an international comparison. Diabet Med 2015;32:1036-50. 